\title{
Scotch Pine Regeneration in Magnesite Pollution Conditions in South Ural, Russia
}

\author{
Pavel Mohnachev ${ }^{1}$, Sergey Menshikov ${ }^{1}$, Svetlana Makhniova ${ }^{1}$, Konstantin Zavyalov ${ }^{1}$, Nadezda Kuzmina ${ }^{1}$, \\ Anton Potapenko², Sezgin Ayan ${ }^{3 *}$, Said Laaribya ${ }^{4}$
}

(1) Institute of the Russian Academy of Sciences Botanical Garden, Ural Branch of Russian Academy of Sciences, 620134, Yekaterinburg, Russia; (2) Institute of Forest of the National Academy of Sciences of Belarus, 246001, Gomel, Republic of Belarus; (3) Kastamonu University, Faculty of Forestry, Department of Silviculture, Kuzeykent Campus, TR-37150 Kastamonu, Turkey; (4) Ibn Zohr University, Campus Ait Melloul, Labo Gedeza, Agadir, Morocco

*Correspondence: e-mail: sezginayan@gmail.com

\begin{abstract}
Citation: MOHNACHEV P, MENSHIKOV $S$, MAKHNIOVA S, ZAVYALOV K, KUZMINA N, POTAPENKO A, AYAN S, LAARIBYA S 2018 Scotch Pine Regeneration in Magnesite Pollution Conditions in South Ural, Russia. South-east Eur for 9 (1): 55-60. DOI: https://doi.org/10.15177/seefor.18-02

Received: 23 Jan 2018; Revised: 11 Feb 2018; Accepted: 20 Feb 2018; Published online: 15 Mar 2018
\end{abstract}

\begin{abstract}
Background and Purpose: Technogenic load is considered to be one of the major factors which destabilize forest ecosystems. The impact of chronic aero technogenic pollution near large industrial centers severely affects the plants in these areas; thus, plants cannot fulfill their aesthetic and air-cleaning role. Therefore, many studies have been carried out on technogenic pollution and particularly on magnesite pollution. The aim of the study is to investigate characteristics of the Scotch pine natural regeneration process under the forest canopy in magnesite pollution conditions.

Materials and Methods: The research was carried in an aero-technogenic emission zone of Kombinat Magnezit, in South Ural, Russia. The purpose is to assess the soil suitability for reforestation in various degrees (PS-2: High pollution zone, PS5: Average pollution zone, PS-3: Low pollution zone, PS-4: Very weak pollution zone, and PS-K: Control area) of magnesite pollution. Experimental Plots (PS) are in similar conditions regarding forest vegetation. The major factors that can influence the natural regeneration, such as the quantity of seeds produced by the parents trees, stand density (the number of trees per 1 ha), the composition of the upper horizon of the soil and height, its density, live ground cover (LGC) phytomass and $\mathrm{pH}$ of the upper root-inhabited soil layer have been measured.

Results: The results of this study showed that in PS-K conditions a large number of seeds, thin forest litter, small phytomass of alive ground cover, and slightly acidic $\mathrm{pH}$ of the root zone of the soil can be found. The dense forest laying, generally composed of fresh and weakly decomposed layers, inhibits seed germination from reaching the mineral soil layer, which results in mortality.

Conclusions: It was evaluated that the success of natural regeneration is effected by the stand density and the occurrence of undergrowth of Scots pine. Soil remediation can positively affect the natural rejuvenation process. Moreover, seed supplementation can play a major role in successful natural rejuvenation.
\end{abstract}

Keywords: aero-technogenic, magnesite pollution, soil toxicity, weed, seeds, natural regeneration

\section{INTRODUCTION}

Natural regeneration is a biological prerequisite of forest longevity as well as the most important indicator of reforestation condition, stability, adaptation extent and reproductive capability. Therefore, the study of forest regeneration in different environments is an important research subject and has a great scientific and practical importance.
Technogenic load is currently considered to be one of the most powerful factors for destabilizing forest ecosystems of boreal zone [1]. Therefore, many studies have been carried out on technogenic pollution [1-3] and particularly on magnesite pollution [4], elevated phytomass [5], the morphological and chemical composition of leaves of pilot cultures (Betula pendula Roth) [6], reproduction [7, 8], and 
the quality of seeds and seed posterities $[9,10]$ of pilot cultures (Pinus silvestris L). These studies suggested the need for reforestation by cultivating pollution-resistant species. Besides, a large number of studies have focused on natural regeneration processes in aero-technogenic pollution conditions [11-15], noting both negative and positive influences of pollutants. Factors such as the total loss or reduction of macrostrobile-forming trees, the increase of the interval between years with high and low potential seed formation on macrostrobile-forming trees, soil toxicity $(\mathrm{pH}$ above 8.5 units), the composition of the top soil horizon and size (poorly decomposed litter and high thickness of the horizon $\mathrm{A} 0$ ), as well as increases or decreases in aerotechnogenic pollution reduce the recovery of Scotch pine or completely stop this natural process. On the contrary, the decrease in maternal forest stand competition, the improvement of temperature and light modes due to crown thinning and tree drop, a decrease in the coenotic role of the moss-lichen cover and the addition of necessary chemical elements to the soil from pollutant emissions can positively effect natural regeneration. The restoration and the regeneration of Scotch pine stands under magnesite conditions have not been studied much. The aim of this study is to determine characteristics of the Scotch pine natural regeneration process under the forest canopy in magnesite pollution conditions.

\section{MATERIALS AND METHODS}

The research was conducted in an aero-technogenic emission zone of Kombinat Magnezit (South Ural, Russia). Kombinat Magnezit is the largest enterprise in Russia for production of fireproof materials. It is located in the city of Satka (Figure 1). The main air pollutant in this area is magnesite dust, which is highly alkaline (average $\mathrm{pH}$ is 10) and mostly comprises magnesium oxide, which breaks down to form $\mathrm{Mg}(\mathrm{OH})_{2}$. High-alkaline magnesite dust and gases (carbon and sulphur oxides) in combined emissions affect the surrounding biology.

Forest stands of Scotch pine cultures planted during the early 1980 s were selected to investigate the natural regeneration process. The purpose of the VNIILM Ural Forest Experimental Station is to assess the soil suitability for reforestation in various degrees of magnesite pollution. Experimental plots (PS) are in similar conditions regarding forest vegetation and are located on the northeast aspect. PS-2 was located $1 \mathrm{~km}$ from the emission source in a high pollution zone (Satka district), PS-5 was in an average pollution zone ( $3 \mathrm{~km}$ from the emission source), PS-3 was in a low pollution zone $(5 \mathrm{~km}$ from the emission source Satka district), PS-4 was in a very weak pollution zone (10 km from the emission source-Berdyaush district) and PS-K was located $20 \mathrm{~km}$ from the combine and represented the background

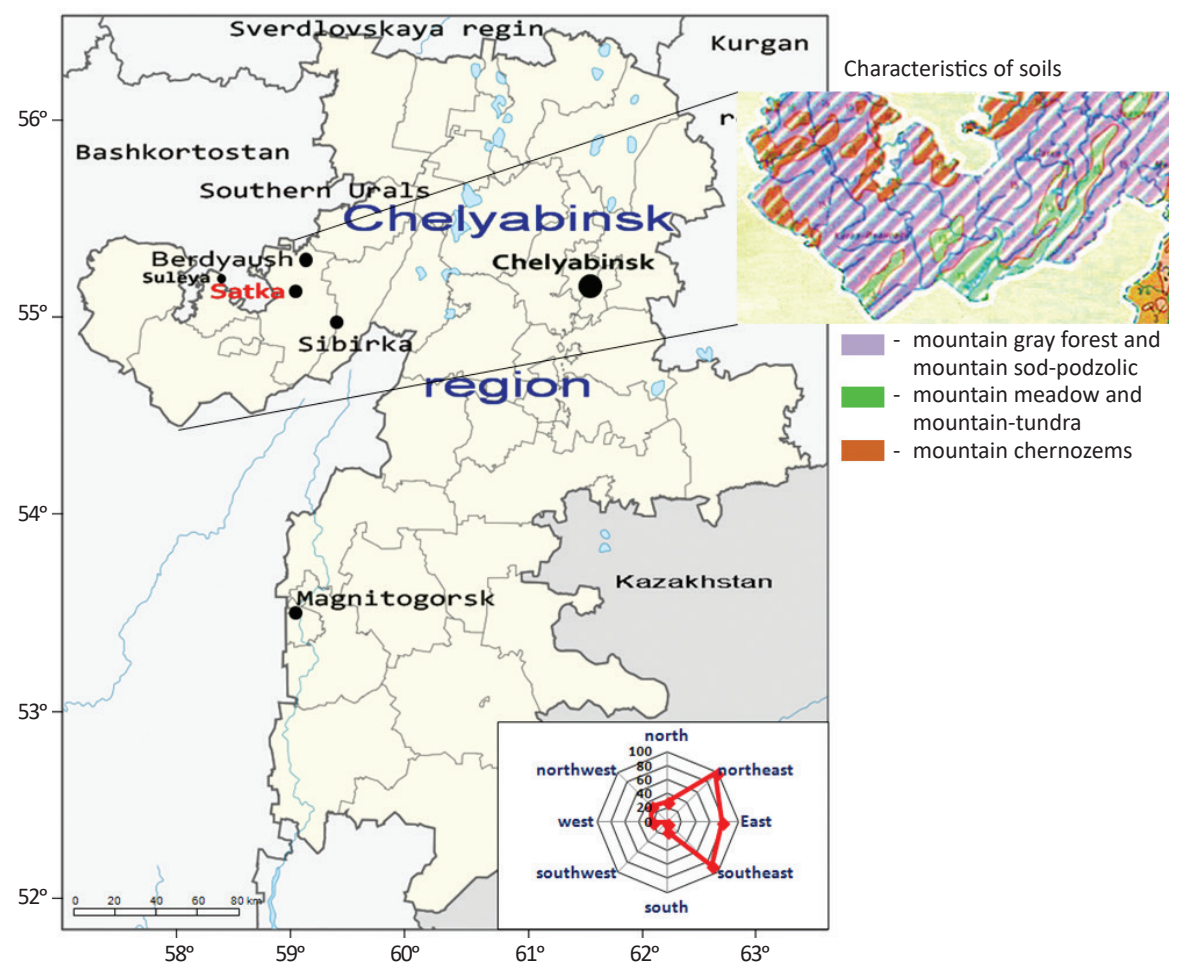

FIGURE 1. The location of the study area, soil types and transforming winds (South Ural, Russia) 
condition (Sibirka district). Detailed descriptions of the PSs, pollution levels and the vegetative and reproductive system conditions of the primary forest species have been provided in previous works [7, 9, 16-18]. Although emissions have been considerably reduced in recent years due to modern raw material conversion technologies and cleaning systems, the reduction in pollution level has not been achieved yet [19].

Standard techniques were used to determine the PS sub-growth $[20,21]$. The total area of each experimental plot is 1 hectare. In experimental plots, $1 \times 1 \mathrm{~m}^{2}$ transects were created between $5 \mathrm{~m}$ interval in the amount of 50 70 pieces on one experimental plot (Figure 2). At each study site, we counted the number of instances of pine, whose age from 1 to 14 years old and then determined the frequency with which such species of pine occur in the area of 1 ha. The occurrence indicator was calculated by using the regeneration occurrence in relation the total number of platforms [22]. This indicator was used to estimate the natural regeneration and the following evaluation criteria were defined: unsatisfactory (25-49\%), satisfactory (50-75\%) and good regeneration (>75\%) [23].

Previous studies identified the major factors that affect the process of natural regeneration under the forest canopy [21, 22, 24-26]. Forest litter thickness on the same registration platform was measured as the sub-growth density. For live ground cover (LGC) selection at each PS, six $1 \times 1 \mathrm{~m}$ registration platforms were placed on a diagonal transect. The LGC phytomass was only identified in dry conditions.
At each PS, the number of seeds carrying trees and parent trees were counted. Seed carrying trees were defined as those with five or more developed macrostrobiles. Upon seed carrying tree identification, the number of macrostrobiles was counted and 5-40 specimens were selected for analysis. Macrostrobile seeds were drilled on their central axes and seed scales were separated to assess the number of full-granular seeds [27]. The quantity of seeds on each tree and in each PS were calculated and converted to a number of seeds per hectare.

\section{RESULTS AND DISCUSSION}

The results revealed that the number of macrostrobileforming trees in the forest changed due to aero-technogenic pollution (Figure 3). In areas with strong, moderate and weak effects of the magnesite pollution, the macro strobil forming trees were $11.19-28.56 \%$ less than the background conditions. The smallest quantity of trees with macrostrobiles was found in the strong pollution zone (PS2), where perennating trees prevail.

The factors that influence the process of natural regeneration under the forest canopy $[7,16,19,22,28]$ are presented in Table 1. Data from a previous study of seedling density and pine sub-growth in an area of magnesite pollution are shown in Table 2.

The results of our study revealed that in background conditions (PS-K) a large number of seeds, thin forest litter, small phytomass of alive ground cover, and slightly acidic $\mathrm{pH}$

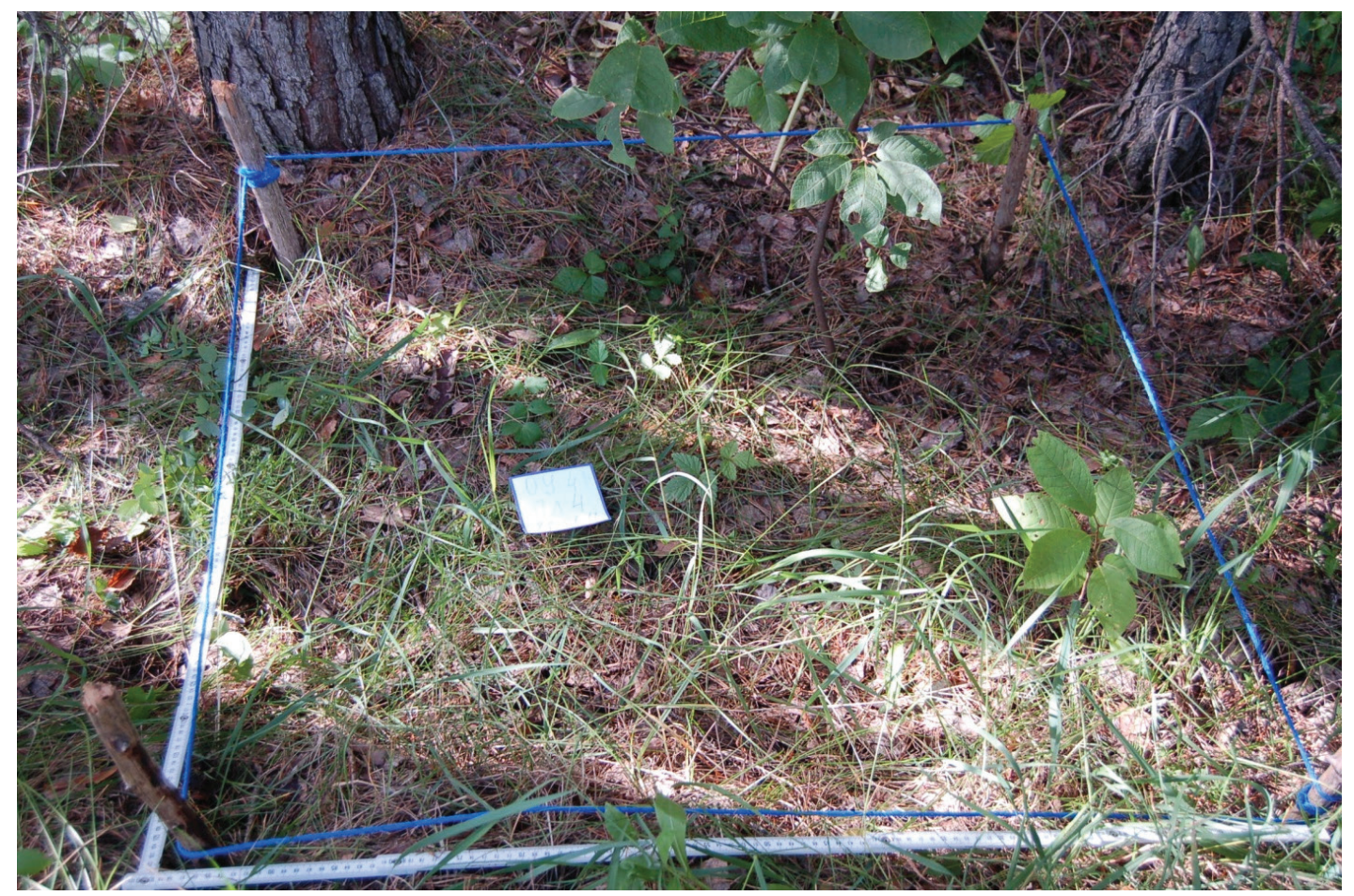

FIGURE 2. Experimental plot 
TABLE 1. Factors that effect the process of natural regeneration under the forest canopy.

\begin{tabular}{|c|c|c|c|c|c|}
\hline $\begin{array}{c}\text { Pilot site / } \\
\text { Distance (km) } \\
\text { from the pollution } \\
\text { source }\end{array}$ & $\begin{array}{l}\text { Stand density } \\
\left(1000 \text { trees }^{\prime} \cdot \text { ha }^{-1}\right)\end{array}$ & $\begin{array}{l}\text { Number of seeds } \\
\left(1000 \text { seeds } \text { ha }^{-1}\right)\end{array}$ & $\begin{array}{c}\text { Forest canopy } \\
\text { thickness } \\
(\mathrm{mm})\end{array}$ & $\begin{array}{l}\text { Phytomass of LGC } \\
\left(\mathrm{kg} \cdot \mathrm{ha}^{-1}\right)\end{array}$ & $\begin{array}{c}\text { pH } \\
\text { (water) } \\
\text { of top root-inhabited } \\
\text { soil layer }(0-20 \mathrm{~cm})\end{array}$ \\
\hline PS- $2 / 1$ & 0.99 & $445.84 \pm 1.2$ & $1.07 \pm 0.10$ & $1663.53 \pm 273.00$ & $9.02 \pm 0,05$ \\
\hline PS-5/3 & 4.42 & $1391.22 \pm 3.9$ & $2.39 \pm 0.21$ & $697.89 \pm 177.26$ & $8.36 \pm 0.05$ \\
\hline PS-3/5 & 1.83 & $797.38 \pm 7.6$ & $4.05 \pm 0.30$ & $355.53 \pm 57.09$ & $7.63 \pm 0.03$ \\
\hline PS-4/10 & 2.39 & $1563.46 \pm 2.07$ & $2.95 \pm 0.25$ & $649.22 \pm 162.17$ & $7.40 \pm 0.05$ \\
\hline PS-K/20 & 2.42 & $3445.96 \pm 1.4$ & $1.80 \pm 0.28$ & $681.47 \pm 144.47$ & $5.88 \pm 0.06$ \\
\hline
\end{tabular}

TABLE 2. Seedling density and pine sub-growth in magnesite pollution conditions.

\begin{tabular}{|c|c|c|c|c|c|c|c|}
\hline \multirow{2}{*}{$\begin{array}{l}\text { Pilot } \\
\text { site }\end{array}$} & \multirow{2}{*}{$\begin{array}{l}\text { Distance from } \\
\text { the emission } \\
\text { source }(\mathrm{km})\end{array}$} & \multicolumn{5}{|c|}{$\begin{array}{l}\text { Average quantity of sub-growth } \\
\left(1000 \text { specimens } \cdot \mathrm{ha}^{-1}\right)\end{array}$} & \multirow{2}{*}{$\begin{array}{l}\text { Total sub-growth, } \\
\text { excluding seedlings } \\
\left(1000 \text { specimens } \cdot h^{-1}\right)\end{array}$} \\
\hline & & $\begin{array}{c}\text { Seedling } \\
\text { ( } 2 \text { years younger) }\end{array}$ & $\begin{array}{c}<0.1 \mathrm{~m} \\
\text { (3-4 years) }\end{array}$ & $\begin{array}{l}0.1-0.5 \mathrm{~m} \\
\text { (5-7 years) }\end{array}$ & $\begin{array}{c}0.6-1 \mathrm{~m} \\
\text { (8-10 years) }\end{array}$ & $\begin{array}{c}1.1-2 \mathrm{~m} \\
\text { (11-14 years) }\end{array}$ & \\
\hline PS-2 & 1 & 0 & $3.00 \pm 0.72$ & $2.33 \pm 0.90$ & 0 & 0 & 5.33 \\
\hline PS-5 & 3 & $1.97 \pm 0.12$ & $19.86 \pm 2.80$ & $13.52 \pm 3.98$ & $2.68 \pm 0.92$ & $0.99 \pm 0.38$ & 37.05 \\
\hline PS-3 & 5 & 0 & $3.8 \pm 0.55$ & $0.6 \pm 0.34$ & $0.2 \pm 0.14$ & 0 & 4.60 \\
\hline PS-4 & 10 & $0.67 \pm 0.29$ & $5.33 \pm 2.10$ & 0 & $0.33 \pm 0.23$ & 0 & 5.66 \\
\hline PS-K & 20 & 0 & 0 & 0 & 0 & 0 & 0 \\
\hline
\end{tabular}

of the root zone of the soil can be found. The dense forest laying, generally composed of fresh and weakly decomposed layers, inhibits seed germination from reaching the mineral soil layer, which results in mortality.

At the very weak pollution level site (PS-4), the subgrowth density was 5.66 thousand specimens/ha. The regeneration process is considered successful with regard to future sub-growth preservation. The lack of sub-growth in age categories of 5-7 years and 11-14 years is significant and can be attributed to the seed carrying frequency. The limiting factor at this site was the forest litter thickness.

At the weak pollution level site (PS-3), the sub-growth density was 4.6 thousand specimens/ha. The regeneration process is considered successful with regard to the future sub-growth preservation. The forest litter thickness and the small quantity of seeds produced by the forest stand impacted the regeneration process at this site.

The highest sub-growth density (37.05 thousand specimens $\cdot \mathrm{ha}^{-1}$ ) was observed at the average pollution level site (PS-5). All age categories of sub-growth were observed and the regeneration is considered successful.

The sub-growth density at the strong pollution level site (PS-2) was 5.33 thousand specimens/ha. The process of regeneration was negatively influenced by the small quantity of seeds, highly-alkaline reaction of the root-inhabited soil layer and the LGC phytomass. At this site, regeneration was possible only where there was no vegetation cover and there were only two age categories of sub-development (i.e. 3-4 years and 5-7 years). The regeneration process can also be considered successful at this site.

TABLE 3. The occurrence of pine sub-growth in magnesite pollution and background conditions.

\begin{tabular}{|c|c|c|c|c|c|c|c|}
\hline \multirow{2}{*}{$\begin{array}{l}\text { Pilot } \\
\text { site }\end{array}$} & \multirow{2}{*}{$\begin{array}{l}\text { Distance from } \\
\text { the emission } \\
\text { source }(\mathrm{km})\end{array}$} & \multicolumn{5}{|c|}{$\begin{array}{l}\text { Average number of reliable sub-growth } \\
\left(1000 \text { specimens }^{\left.-h^{-1}\right)}\right.\end{array}$} & \multirow{2}{*}{$\begin{array}{l}\text { Occurrence } \\
(\%)\end{array}$} \\
\hline & & $\begin{array}{c}\text { Seedling } \\
\text { (2 years younger) }\end{array}$ & $\begin{array}{c}<0.1 \mathrm{~m} \\
\text { (3-4 years) }\end{array}$ & $\begin{array}{l}0.1-0.5 \mathrm{~m} \\
\text { (5-7 years) }\end{array}$ & $\begin{array}{c}0.6-1 \mathrm{~m} \\
(8-10 \text { years })\end{array}$ & $\begin{array}{c}1.1-2 \mathrm{~m} \\
\text { (11-14 years) }\end{array}$ & \\
\hline PS-2 & 1 & 0 & 13.3 & 20.0 & 0 & 0 & 26.7 \\
\hline PS-5 & 3 & 12.7 & 39.4 & 29.6 & 14.8 & 5.6 & 62.0 \\
\hline PS-3 & 5 & 0 & 26.0 & 6.0 & 2.0 & 0 & 28.0 \\
\hline PS-4 & 10 & 3.3 & 10.0 & 0 & 3.3 & 0 & 13.3 \\
\hline PS-K & 20 & 0 & 0 & 0 & 0 & 0 & 0 \\
\hline
\end{tabular}


A decrease in the sub-growth density with a corresponding increase of age variable characterises each PS. The low quantity (or absence) of seedlings in each PS is associated with the low harvests in 2011 and 2012. The high number of 3-4 year old sub-growth specimens coincides with 2009 and 2010, in which high yields were achieved.

The occurrence of pine sub-growth in magnesite pollution and background conditions is provided in Table 3. Occurrence coefficient indicators characterise the natural regeneration process as satisfactory at the average pollution level in experimental plot PS-5 and unsatisfactory in all other experimantal plots. This result can be explained by the stand densities and seed amounts.

Scotch pine, a widely distributed and important forest-forming tree, is characterized by high sensitivity to technogenic polluting agents [29]. Sazonova and Olchev [30] emphasized that comparisons of the responses of Picea obovata Ledeb. and Pinus sylvestris L. trees to industrial pollution showed that a relationship between tree vitality status shown by visual traits and by physiological criteria was more evident for $P$. obovata than $P$. sylvestris trees. Thus, spruce may be less resistant to pollution than pine trees [31]. Silver birch and Scotch pine trees were more severely impacted by dust pollution compared to Sukachyov's larch trees. Soil remediation is required in strongly affected areas. The use of $12 \mathrm{~cm}$ thick peat layers in the soil mitigates the pollution impact on plant growth [32].

Air pollution resulted in increased defoliation and decreased three growth. Trees closer to the source of emissions are most severely damaged. With increasing pollution, the lifespan of Scotch pine needles is reduced by $40 \%$ in comparison with the same species at the control site [32].

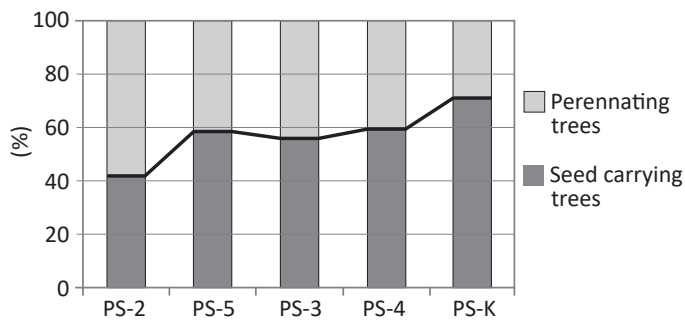

FIGURE 3. The share of seed carrying trees on the pilot sites (PS).

\section{CONCLUSIONS}

Our research showed that in background conditions natural regeneration of Scotch pine is completely absent. However, the quantities of pine sub-growth at all levels of magnesite pollution were sufficient for natural regeneration and the process was successful with regard to the future subgrowth preservation. Furthermore, the average pollution level in experimental plot PS-5 had the largest amount of sub-growth and was the only site with a satisfactory occurrence indicator. The relationship between soil and plants, under the influence of the accumulated aerial technogenic impacts of emissions in polluted areas, should be examined comprehensively for a long time.

\section{Acknowledgement}

The work was carried out within the framework of the State task of the Botanical Garden of the Ural Branch of the Russian Academy of Sciences.

\section{REFERENCES}

1. SMITH WH 1985 Forest and Atmosphere. Interaction between Forest Ecosystems and Atmospheric Impurities. Progress, Moscow, $430 \mathrm{p}$ (Russian translation)

2. GUDERIAN R 1979 Air Pollution. Mir, Moscow. 200 p (in Russian)

3. BURTON J 1986 Robert Fitzroy and the early history of the Meteorological Office. British Journal for the History of Science 19 (2) 147-176. DOI: https://doi.org/10.1017/ S0007087400022949

4. ZAVYALOV KE, MENSHIKOV SL 2009 Condition of birch cultures in the conditions of magnesite pollution. Agricultural Russia Special issue: 60-61 (in Russian)

5. ZAVYALOV KE, MENSHIKOV SL 2010 Over ground phytomass of pilot cultures of the birch in conditions of magnesite dust pollution. Izvestia of Orenburg State Agrarian University 28 (4) 27-30 (in Russian)

6. ZAVYALOV KE 2013 Morphology and chemical composition of leaves of pilot cultures of the silver birch (Betula pendula Roth) in the conditions of magnesite pollution. Izvestia of Orenburg State Agrarian University 41 (3): 230-232 (in Russian)

7. MOHNACHEV PE, MAKHNEVA SG, MENSHCHIKOV SL 2013 Features of reproduction of the Scotch pine (Pinus silvestris L.) in the conditions of pollution by magnesite dust. Izvestia of Orenburg State Agrarian University 41 (3) 8-9 (in Russian)
8. MOHNACHEV PE 2014 Female generative sphere of the Scotch pine in the conditions of magnesite pollution. Materials of the All-Russian scientific conference with the international participation devoted to the 70 anniversary of creation of V. N. Sukachyov Institute of Forests of the Siberian Branch of the Russian Academy of Sciences: Forest biogeocenoses of the Boreal zone: geography, structure, functions, dynamics, Krasnoyarsk, 2014. Novosibirsk: Publishing house of the Siberian Branch of the Russian Academy of Sciences: 348-351

9. MAKHNEVA SG, MOHNACHEV PE, MENSHCHIKOV SL 2013 Influence of soil conditions and the origin of seeds of the Scotch pine on their laboratory and soil viability. Izvestia of Orenburg State Agrarian University 41 (3) 10-12 (in Russian)

10. MAKHNIOVA SG, MOHNACHEV PE 2014 Quality of seed posterities of the Scotch pine of different origins on the leveled ecological background. Forest biogeocenoses of the Boreal zone: geography, structure, functions, and dynamics. Novosibirsk, Publishing house of the Siberian Branch of the Russian Academy of Sciences: 343-346 (in Russian)

11. ALEKSEEV VA DOCHINZHER LS 1981 Forest ecosystems and atmospheric pollution. Lesovedeniye 5: 64-71 
12. VOROBEYCHIK EL, SADYKOV OF, FARAFONTOV MG 1994 Ecological regulation of technogenic pollution of land ecosystems (local level). UIF "Science". Yekaterinburg, 280 $\mathrm{p}$

13. MENSHCHIKOV SL 1985 Research of ecological features of growth and reasons for agro technology of creation of cultures of coniferous breeds in the conditions of magnesite dust: Author's abstract on competition of a PhD agriculture sciences thesis. Sverdlovsk, $20 \mathrm{p}$

14. FEDORKOV AL 1992 A sexual reproduction of the Scotch pine in case of aero technogenic pollution in the conditions of the Subarctic region. Forest magazine 4: 60-64

15. TSVETKOV VF, TSVETKOV IV 2003 Forest in the conditions of aero technogenic pollution. Arkhangelsk: OGUP Solombalsky Typography, $354 \mathrm{p}$

16. ZAVYALOV KE 2009 The condition of artificial plantations of the silver birch (Betula pendula Roth) in the conditions of magnesite pollution: avtoref. diss. cand. agricult. sciences. Yekaterinburg, $16 \mathrm{p}$

17. ZAVYALOV KE 2015 Condition of pine forest stands of the green zone of Satka, subject to aero technogenic emissions of magnesite production. Izvestia Orenburg State Agrarian University 56 (6) 57-59

18. KUZMINA NA, MENSHCHIKOV SL 2015 Impact of agrotechnogenic emissions of magnesite production on the chemical composition of snow water and soil in dynamics. Izvestia Orenburg State Agrarian University 56 (6) 192-195 (in Russian)

19. MENSHCHIKOV SL, KUZMINA NA, MOHNACHEV PE 2012 Impact of atmospheric emissions of magnesite production on soils and snow cover. Izvestia Orenburg State Agrarian University 5 (37) 221-223 (in Russian)

20. POBEDINSKY AV 1966 Studying of reforestation processes. Moscow: Nauka. 64 p.

21. SANNIKOV SN, SANNIKOVA NS 1985 Ecology of natural renewal of the pine under the forest canopy. Moscow: Nauka.149 p
22. BELOV SV 1983 Forestry. Moscow: Wood industry. $52 \mathrm{p}$

23. SANNIKOV SN, BARANTSEV AS 1983 Way of assessment of natural renewal. Forestry 10: $38 \mathrm{p}$ (in Russian)

24. LUHANSKY NA, ZALESOV SV, SHCHAVROVSKY VA 1996 Lesovedeniye: Education guidance. Ural. State. for. Academy. Yekaterinburg. $373 p$

25. SANNIKOV SN 1992 Ecology and geography of natural renewal of the Scotch pine. Moscow: Nauka, 264 p.

26. SANNIKOVA NS 2009 Features of renewal of the pine after fires under bed curtains of pine forests of the forest-steppe of Western Siberia. Russian Journal of Forest Science (4) 58-65

27. ROMANOVSKY MG 1997 Forming of the harvest of seeds of the pine in the norm in case of mutagen pollution. Moscow: Nauka,112 p

28. MENSHCHIKOV SL, BARANOVSKY VV, KUZMINA NA 2013 Density of subgrowth of the Scotch pine after the local fires in the zone of aero technogenic pollution. Russian Journal Ecology 44 (5) 367-370

29. MIKHAILOVA TA 2000 The physiological condition of pine trees in the Prebaikalia (East Siberia). Forest Pathol 30 (6) 345-359. DOI: https://doi.org/10.1046/i.14390329.2000.00221.x

30. SAZONOVA TA, OLCHEV AV 2010 The response of coniferous tress to industrial pollution in North-Western Russia. The Open Geography Journal 3: 125-130. DOI: https://doi.org/ 10.2174/1874923201003010125

31. MIKHAILOVA TA, SHERGINA OV, KULAGINA OV 2015 Indicative indicators of violation of forest ecosystems technogenic pollution. International Journal of Applied and Fundamental Research 2: 78-82

32. ZAVYALOV KE, MENSHIKOV S, MOHNACHEV P, KUZMINA N, POTAPENKO A, AYAN S 2018 Response of Scotch pine, Sukachyov's larch, and silver birch to magnesite dust in Satkinsky industrial hub. Forestry Ideas 24 (1) (Accepted) 